ORIGINAL ARTICLE

\title{
Interference in Serum Lithium Estimation by Silica Clot Activator and Silicone Surfactant in ISE Principle: a Cross-Sectional Study
}

\author{
L Naznin ${ }^{1}$, D Saha ${ }^{2}$, S Sultana ${ }^{2}$, MMK Sarkar ${ }^{2}$ \\ ${ }^{1}$ Combined Military Hospital, Ghatail \\ ${ }^{2}$ Armed Forces Institute of Pathology, Dhaka
}

\begin{abstract}
Serum lithium concentration is monitored to ensure patient's compliance and to avoid intoxication and thus it is a prerequisite for an individual's dose adjustment. An unavoidable error during lithium estimation in blood collected in 'red-top plastic vacutainer plus tube containing silica clot activator and silicone surfactant' by ISE appeared as a reality for a standard laboratory like AFIP. The error could not be detected even by proven internal and external QC. This cross-sectional study was carried out at AFIP Chemical Pathology Department from May' 2015 to July'2015 to find out the interference causing falsely elevated serum lithium concentration by ISE principle. Blood were collected from the 40 study subjects including 30 healthy volunteers, who never took Tab Lithium and 10 patients, who used to take Tab Lithium for bipolar mood disorder in both 'plain red-top plastic vacutainer tubes without additive' as well as 'plain red-top plastic vacutainer plus tube containing silica clot activator and silicone surfactant'. Lithium concentrations were estimated in both types of tubes by Ion-Selective Electrode (ISE) principle employing world class, USA manufactured analyzer NOVA-4 as well as by colorimetric method using Dade Dimension, Siemens. Serum lithium concentrations were undetectable for the 'lithium-free normal volunteers' in both types of tubes measured by colorimetry but in ISE principle it was undetectable when collected in plain test tube without additives but when collected in 'vacutainer plus tube containing silica clot activator and silicone surfactant' and measured by ISE technique, the mean serum lithium concentration was found to be $1.78 \pm 0.40 \mathrm{mmol} / \mathrm{l}$. Besides, mean serum lithium concentration of 10 individuals taking Tab Lithium had no statistically significant difference while measured by ISE or colorimetry in 'vacutainer tubes without additive' and also in 'vacutainer plus tubes containing silica clot activator and silicone surfactant' measured by colorimetry. But, vacutainer plus tubes containing silica clot activator and silicone surfactant' while measured serum lithium concentration by ISE principle had significant $(p<0.001)$ increase in mean concentration than others, as determined by one-way ANOVA and Post-hoc tests. This study demonstrates that positive interference; caused by silica clot activator and silicone surfactant of the collection tubes; increases measured concentration of lithium. This interference; being in the pre-analytic phase, cannot be detected by routinely performed laboratory quality control.
\end{abstract}

Key Words: Lithium, ISE, Colorimetry

\section{Introduction}

Lithium has been in use over half a century in the treatment of bipolar disorder as a traditional mood stabilizer. It is effective in the treatment of acute mania and for the long-term maintenance of mood and as prophylaxis; in comparison, evidence for its efficacy in depression is modest. However, lithium Bangladesh J Med Biochem 2015; 8(2): 60-65 possesses unique anti-suicidal properties that set it apart from other agents ${ }^{1}$. Serum lithium concentrations are monitored to ensure patient compliance and to avoid intoxication because of its narrow safety margin ${ }^{2}$. It has been recommended that a standardized 12-hour post-dose serum lithium 
Interference in Serum Lithium Estimation by Silica Clot Activator

concentration be used to assess adequate therapy ${ }^{2}$. Therapeutic level ranges between 0.6 and $1.2 \mathrm{mmol} / \mathrm{l}^{3}$ and the interval 1.0 to $1.2 \mathrm{mmol} / \mathrm{l}$ was identified as the optimal therapeutic concentration ${ }^{2}$. Concentrations 1.2 to $1.5 \mathrm{mmol} / \mathrm{l}$ signifies a warning range, and a concentration more than $1.5 \mathrm{mmol} / \mathrm{l}$ indicates a significant risk of intoxication2. Methods in use for serum lithium determination are Flame Emission Photometry (FEP), Atomic Absorption Spectroscopy (AAS), Ion Selective Electrode (ISE) and colorimetry $^{4,5}$. ISE and colorimetric methods are suitable to the ubiquitous clinical analyzers used in laboratories ${ }^{4,5}$.

AFIP Chemical Pathology Department encountered a Patient's serum received in eppendrof on 10th May'2015 after collecting the specimen at a hospital. The patient was a known case of 'Bipolar disorder' and was receiving tablet lithium for a considerable period of time. Serum Lithium concentration was found to be $2.4 \mathrm{mmol} / \mathrm{l}$ in the context of therapeutic range 0.6-1.2 mmol/1. Though Serum Lithium concentration was in the level of 'significant risk of intoxication' the patient was asymptomatic. So, this time serum sample of the same patient in eppendrof was sent to AFIP as well as to another reputed laboratory on 12th May. AFIP found Serum Lithium concentration $2.1 \mathrm{mmol} / 1$ i.e. in 'significant risk limit' where as the other lab found the concentration $0.6 \mathrm{mmol} / \mathrm{l}$ i.e. within therapeutic range. So, the confused patient then stopped taking Lithium dosage. Then serum sample of the same patient in eppendrof was sent to AFIP and to three other reputed laboratories on 24th may and results of Serum Lithium concentration were in AFIP: $1.7 \mathrm{mmol} / \mathrm{l}$, in the 1st lab: $0.4 \mathrm{mmol} / \mathrm{l}$, in the $2 \mathrm{nd} \mathrm{lab:} 0.6 \mathrm{mmol} / \mathrm{l}$ and in the 3rd lab: $0.4 \mathrm{mmol} / \mathrm{l}$ against the same therapeutic range of $0.6-1.2 \mathrm{mmol} / 1$. So, it was obvious that the Serum Lithium result of AFIP was quite higher than other laboratories. This time that hospital willfully sent a serum sample of one of their physicians in eppendorf, who was never known to take Tab Lithium till 27th May 2016. As before, AFIP Serum Lithium concentration was higher, found in 'warning limit' of $1.5 \mathrm{mmol} / \mathrm{l}$. So, they notified AFIP Chemical Pathology Department about the fact. At first, the Department was in a state of shock. But, the strength was that AFIP had been performing serum Lithium concentration assay for more than a decade by ISE (Ion Selective Electrode) principle using USA manufactured world class analyzer NOVA-4 with no previous report of error. Besides, NOVA-4 is also in use for serum electrolyte estimation. So, a high degree of quality control is always carefully ensured by 2 hourly autocalibrations. If the analyzer is uncalibrated for any of its performing parameters, that parameter cannot be estimated or reported. Moreover the Department's confidence was further strengthened by its excellent 'Internal Quality Control' as well as by the proven performance in 'External Quality control' under UK (United Kingdom) RANDOX. Definitely QC is the ultimate determining strength for any laboratory. So, the Department took the observation seriously and worked over it. This time the Department asked for another sample from that patient. Calibrator and control were run with special attention. Patient's sample was measured in replicate for thrice. All three results were found to be high beyond the therapeutic range though the patient omitted the drugs. The Department then collected specimens at AFIP from 'the volunteers of AFIP' (technicians and pathologists), who never took Tab Lithium. The results of the volunteers were below analyzer assay range i.e. undetectable, indicating that the analyzer performance was well. So, it was obvious for that specific patient error was somewhere, but where? No clue to reach the light, making the biochemist confused what to do? Then a clue came from a journal $^{1}$ that positive interference occurs with the ionselective electrode based determination of lithium when blood is collected in a $10-\mathrm{ml}$ plain red-top plastic vacutainer plus tube containing silica clot activator and silicone surfactant. AFIP Chemical Pathology Department, then considered collection tube might be a possible source of interference because all the collection tubes were from that hospital and afterwards sent in eppendrofs to AFIP. This time the Department asked some empty collection tubes from that hospital and noticed that the tubes were 'vacutainer plus tubes' containing 'silica clot activator and silicone surfactant; in contrast tubes in use at AFIP are vacutainer tubes with 'no additive'. The present study was designed to demonstrate the interference due to specimen collection tube in serum lithium estimation by ISE. 


\section{Materials and Methods}

In this cross-sectional study, 40 subjects were selected, among them 30 healthy volunteers, who never took Tab Lithium and 10 patients used to take Tab Lithium for bipolar mood disorder and were referred to AFIP for serum lithium estimation. The study was carried out from May 2015 to July 2015 at Chemical Pathology Department, AFIP. Blood specimens were collected from the study subjects in both 'plain red-top plastic vacutainer tubes without additive' (plain tube) as well as 'plain red-top plastic vacutainer plus tubes containing silica clot activator and silicone surfactant' (tube with clot activator). Informed consents were obtained from all the study subjects.

Serum lithium were estimated in blood collected in both types of tubes with and without additives by Ion-Selective Electrodes (ISEs) using NOVA-4, USA. It is based on a special-purpose, potentiometric electrode consisting of a membrane selectively permeable to a single ionic species i.e. lithium. The potential produced at the membranesample solution interface is proportional to the logarithm of the lithium activity or concentration. Besides, serum lithium was also measured in both groups of tubes by colorimetric method using Dade Dimension, Siemens in which lithium present in the sample reacts with porphyrin at an alkaline $\mathrm{pH}$, resulting in a change in absorbance which is directly proportional to the concentration to the lithium in the sample.

\section{Results}

Serum lithium concentration of lithium-free normal volunteers in case of blood collected in 'plain tubes' consistently gave results below analytical assay range i.e. undetectable by the ISE analyzer. Whereas, for the same, blood collected in 'tubes with clot activator' the serum lithium measured by ISE found mean concentration to be $1.78 \pm 0.40 \mathrm{mmol} / \mathrm{l}$, with minimum $1.18 \mathrm{mmol} / \mathrm{l}$ and maximum $2.71 \mathrm{mmol} / \mathrm{l}$, though their serum actually should be undetectable for lithium. Comparison of serum lithium concentration results in these two groups found statistically highly significant $(\mathrm{p}<0.0001)$ with $95 \%$ confidence interval. When identical sera in both types of tubes with and without clot activator were estimated for lithium concentration by colorimetric method using 'Dade Dimension' then all the results were below analytical assay range i.e. undetectable for both types of tubes. (Table 1)
Table-I: Serum Lithium of 30 healthy volunteers (who never took Tab Lithium)

\begin{tabular}{|c|c|c|c|c|}
\hline & Nova & 4 & Dade Dim & ension \\
\hline Tube & es without additive ac & $\begin{array}{l}\text { Tubes with silica clot } \\
\text { activator and siliconesurfactan }\end{array}$ & $\begin{array}{l}\text { Tubes without } \\
\text { nt additive }\end{array}$ & $\begin{array}{l}\text { Tubes with silicaclot } \\
\text { activator and silicone } \\
\text { surfactant }\end{array}$ \\
\hline 1 & U ndetectable & 1.97 & undetectable & Undetectable \\
\hline 2 & U ndetectable & 2.14 & undetectable & Undetectable \\
\hline 3 & U ndetectable & 2.17 & undetectable & Undetectable \\
\hline 4 & U ndetectable & 2.61 & undetectable & Undetectable \\
\hline 5 & U ndetectable & 1.41 & undetectable & Undetectable \\
\hline 6 & U ndetectable & 1.59 & undetectable & Undetectable \\
\hline 7 & U ndetectable & 2.71 & undetectable & Undetectable \\
\hline 8 & U ndetectable & 1.80 & undetectable & Undetectable \\
\hline 9 & U ndetectable & 1.57 & undetectable & Undetectable \\
\hline 10 & U ndetectable & 1.28 & undetectable & Undetectable \\
\hline 11 & U ndetectable & 1.24 & undetectable & Undetectable \\
\hline 12 & U ndetectable & 1.26 & undetectable & Undetectable \\
\hline 13 & U ndetectable & 2.19 & undetectable & Undetectable \\
\hline 14 & U ndetectable & 1.18 & undetectable & Undetectable \\
\hline 15 & U ndetectable & 2.09 & undetectable & Undetectable \\
\hline 16 & U ndetectable & 1.97 & undetectable & Undetectable \\
\hline 17 & U ndetectable & 1.78 & undetectable & Undetectable \\
\hline 18 & U ndetectable & 1.62 & undetectable & Undetectable \\
\hline 19 & U ndetectable & 1.95 & undetectable & Undetectable \\
\hline 20 & Undetectable & 2.29 & undetectable & Undetectable \\
\hline 21 & Undetectable & 2.02 & undetectable & Undetectable \\
\hline 22 & Undetectable & 1.39 & undetectable & Undetectable \\
\hline 23 & Undetectable & 1.89 & undetectable & Undetectable \\
\hline 24 & Undetectable & 1.29 & undetectable & Undetectable \\
\hline 25 & Undetectable & 1.96 & undetectable & Undetectable \\
\hline 26 & Undetectable & 2.07 & undetectable & Undetectable \\
\hline 27 & Undetectable & 1.67 & undetectable & Undetectable \\
\hline 28 & Undetectable & 1.34 & undetectable & Undetectable \\
\hline 29 & Undetectable & 1.52 & undetectable & Undetectable \\
\hline 30 & Undetectable & 1.60 & undetectable & Undetectable \\
\hline
\end{tabular}

Again, lithium concentration of 10 individuals, who used to take Tab Lithium in blood collected in 'plain tubes' and measured by ISE using Nova-4 had mean concentration of $0.57 \pm 0.22$ 
Interference in Serum Lithium Estimation by Silica Clot Activator

$\mathrm{mmol} / \mathrm{l}$, minimum $0.32 \mathrm{mmol} / \mathrm{l}$ and maximum $0.90 \mathrm{mmol} / \mathrm{l}$. In contrast, the lithium concentration of those 10 individuals in blood collected in 'tubes with clot activator' by Nova-4 had mean concentration of $2.80 \pm 0.69 \mathrm{mmol} / 1$, minimum $1.86 \mathrm{mmol} / \mathrm{l}$ and maximum 3.76 mmol/l. On the other hand, the same measurements by colorimetric principle using Dade Dimension in 'plain tubes' had mean concentration of $0.59 \pm 0.19 \mathrm{mmol} / 1$, minimum $0.35 \mathrm{mmol} / \mathrm{l}$ and maximum $0.88 \mathrm{mmol} / \mathrm{l}$ and in 'tubes with clot activator' had mean concentration of $0.60 \pm 0.20 \mathrm{mmol} / 1$, minimum $0.36 \mathrm{mmol} / \mathrm{l}$ and maximum $0.86 \mathrm{mmol} / \mathrm{l}$ (Table II).

Table-II: Serum Lithium of 10 patients (who used to take Tab Lithium)

\begin{tabular}{|c|c|c|c|c|}
\hline & \multicolumn{2}{|c|}{ Nova 4} & \multicolumn{2}{|c|}{ Dade Dimension } \\
\hline & $\begin{array}{l}\text { Group } 1 \\
\text { Tubes without } \\
\text { additive (by ISE) }\end{array}$ & $\begin{array}{l}\text { Group } 2 \\
\text { Tubes with silica clot } \\
\text { activator and silicone } \\
\text { surfactant (by ISE) }\end{array}$ & $\begin{array}{l}\text { Group } 3 \\
\text { Tubes without } \\
\text { additive (by colorimetry) }\end{array}$ & $\begin{array}{l}\text { Group } 4 \\
\text { Tubes with silicaclot } \\
\text { activator and } \\
\text { silicone surfactant } \\
\text { ( by colorimetry) }\end{array}$ \\
\hline Lithium & $\mathrm{mmol} / \mathrm{L}$ & $\mathrm{mmol} / \mathrm{L}$ & $\mathrm{mmol} / \mathrm{L}$ & $\mathrm{mmol} / \mathrm{L}$ \\
\hline $\begin{array}{l}\text { Mean } \\
\text { concentration }\end{array}$ & 0.57 & 2.80 & 0.59 & 0.60 \\
\hline $\begin{array}{l}\text { Standard } \\
\text { Deviation }\end{array}$ & 0.22 & 0.69 & 0.19 & 0.20 \\
\hline $\begin{array}{l}\text { Minimum } \\
\text { concentration }\end{array}$ & 0.32 & 1.86 & 0.35 & 0.36 \\
\hline $\begin{array}{l}\text { Maximum } \\
\text { concentration }\end{array}$ & 0.90 & 3.76 & 0.88 & 0.86 \\
\hline $\begin{array}{l}\text { Median } \\
\text { concentration }\end{array}$ & 0.54 & 2.80 & 0.57 & 0.58 \\
\hline
\end{tabular}

One-way ANOVA demonstrated statistically significant $(p<0.001)$ difference between the groups and Post-hoc tests revealed significant difference ( $\mathrm{p}$ $<0.001$ ) between mean lithium concentration in 'tubes with clot activator' by ISE using NOVA-4 (Group 2) to 'plain tubes' by ISE, NOVA-4 (Group 1) and also to 'plain tubes' by colorimetry using Dade Dimension (Group 3) as well as to 'tubes with clot activator' (Group 4) by colorimetry using Dade Dimension, Siemens. But no significant differences were observed in mean concentrations of serum lithium among Group 1, Group 3 and Group 4 (Table-III).
Table-III: Post-hoc tests to demonstrate differences among the groups

\begin{tabular}{llll}
\hline & Difference & 95\% Confidence Interval & p- value \\
\hline Group 1 vs Group 2 & 2.2200 & 1.7533 to 2.6867 & $<0.001$ \\
Group 1 vs Group 3 & 0.0200 & 0.4467 to 0.4867 & 0.9994 \\
Group 1 vs Group 4 & 0.0300 & 0.4367 to 0.4967 & 0.9981 \\
Group 2 vs Group 3 & 2.2000 & 2.6667 to -1.7333 & $<0.001$ \\
Group 2 vs Group 4 & 2.1900 & 2.6567 to -1.7233 & $<0.001$ \\
Group 3 vs Group 4 & 0.0100 & 0.4567 to 0.4767 & 1.0000 \\
\hline
\end{tabular}

Group 1: Tubes without additive by ISE

Group 2: Tubes with silica clot activator and silicone surfactant by ISE

Group 3: Tubes without additive by colorimetry

Group 4: Tubes with silica clot activator and silicone surfactant by colorimetry

So, blood collection tubes 'vacutainer plus tubes with silica clot activator and silicone surfactant' was proved to be the source of positive interference for lithium estimation by ISE method.

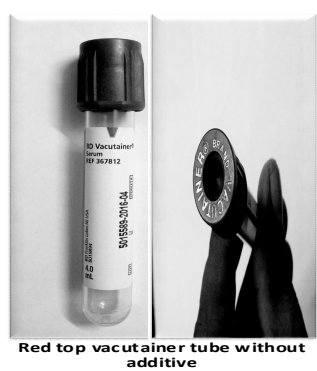

Fig 1. Red top vacutainer tube without additive

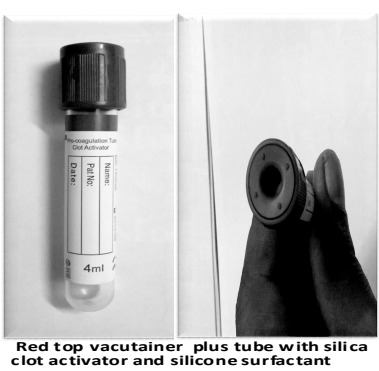

Fig 2. Red top vacutainer plus tube with silica clot activator and silicone surfactant

\section{Discussion}

ISE (ion selective electrode) technology is based on the use of electrochemical sensor. Ion selective membrane is the 'heart' of ISE, controlling the selectivity of electrode ${ }^{6}$. In case of 'lithium electrode sensor' electric potential is generated at the membrane- sample interface in response to serum lithium concentration. The 
generated electric potential is proportional to logarithm of lithium activity or lithium concentration. This electric potential is compared with reference electrode having the constant electric potential. The potential difference is then expressed as lithium concentration ${ }^{7}$. In case of 'vacutainer plus tubes' the silica clot activator and silicone surfactant appears to interact with lithium ion-specific analyzer membranes, which increase the measured voltage/potential and falsely elevate serum lithium ion concentration ${ }^{7,8}$.

In this study, the result of mean lithium concentration of serum collected in tubes without additive are decreased by $79.6 \%$ than serum collected in tubes with silica clot activator and silicone surfactant. Maureen Sampson et $\mathrm{al}^{7}$, in his study showed lithium concentrations in serum without silica clot activator (SCA) are decreased by $20 \%$. Such a greater decrease in lithium concentration in tubes without additive in our study may be due to volume of blood collected in the vacutianer tubes, as blood volume is inversely related to the apparent Lithium concentration ${ }^{7}$.

Vacutainer tubes supplied by different manufacturers vary in the materials and additives that can potentially affect the test performance. Silicone surfactant coated tubes have been shown to interfere with ion-specific electrode measurement of not only lithium but also of ionized magnesium ${ }^{7,8}$ through interaction with ionspecific electrode membranes leading to increase in the measured voltage. In addition, water-soluble silicone polymer coatings in separator tubes can physically mask antibodies and alter avidin-biotin binding reactions in immunoradiometric assays ${ }^{8}$.

Laboratories other than AFIP, Chemical Pathology Department performed serum lithium estimation by a colorimetric method readily adapted to automated clinical chemistry analyzers (Dade Dimension, Siemens). In this method lithium present in the sample reacts with a substituted porphyrin compound at an alkaline $\mathrm{pH}$, resulting in a change in color which is directly proportional to the concentration of
Lithium in the sample. So, this method being a colorimetric method is not affected by ions like silica clot activator and silicone surfactant. onSelective Electrodes (ISEs) principle of NOVA4 analyzer of AFIP is based on the measurement of voltage/potential, is affected by ions like silica clot activator and silicone surfactant. So, the results from AFIP didn't match with those of other laboratories. Components from blood collection tubes, such as stoppers, lubricants, surfactants, and separator gels can leach into specimens and/or adsorb analytes from a specimen; special tube additives may also alter analyte stability8. Because of these interactions with blood specimens, blood collection devices are a potential source of pre-analytical error in laboratory testing. So, accurate and precised laboratory test results demand understanding and consideration of such complex interactions between collection devices and blood specimens.

Inconclusion, preanalytical factor i.e. collection in tubes containing silica clot activator and silicone surfactant, was the cause behind the elevated serum lithium concentration by ISE technique in our study. Laboratory personnel should be aware of the potential problems that collection tubes can be a source of interference, which adversely influence test results. Such blood collection device problems may go unnoticed by laboratory personnel since routine quality control (QC) practice typically does not assess or fail to detect blood collection device problems. Erroneous result regardless of background cause affects physician's decision; patient's outcome and demands repeat testing causing delay in reporting of test results and make confusion. So, optimization and standardization of collection tubes are vital for the reliable test results. Tube manufacturers, diagnostic companies, and clinical laboratory manager must consider such pre-analytical challenges. Further studies should be done on other factors influencing or modifying lithium interference in ISE principle. 
Interference in Serum Lithium Estimation by Silica Clot Activator

\section{References}

1. Malhi GS, Tanious M, Das P, Coulston CM, Berk M. Potential mechanisms of action of lithium in bipolar disorder. Current understanding. CNS DRUGS 2013; 27(2): 135-53. doi: 10.1007/s40263013-0039-0.

2. Carl A. Burtis, Edward R. Ashhood, David E. Bruns. Tietz's Fundamentals of Clinical Chemistry. $6^{\text {th }}$ edn, Elsevier Saunders 2008; 556-557.

3. Carlos Elielton do Espírito Santo, Teresa Maria de Jesus Ponte Carvalho. Determination of serum lithium: comparison between atomic emission and absorption spectrometry methods. J Bras Pathol Med Lab 2014; 50(1): 12-19.

4. Gruson D, Lallali K , Conti A, Legrand A, Gruson PE. Clinical laboratory requirements for lithium assays and future of lithium assays. Trace Elements and Electrolytes 2007; 24(01): 6-12. DOI: $10.5414 /$ TEP 24005
5. Gruson D, Lallali A, Furlan V, Taburet AM, Legrand A, Conti M. Evaluation of a new lithium colorimetric assay performed on the dade behring dimension X-pand system. Clin Chem Lab Med 2004; 42(9): 1066-1068.

6. Carl A. Burtis, Edward R. Ashhood, David E. Bruns. Tietz's Fundamentals of Clinical Chemistry. $6^{\text {th }}$ edn, Elsevier Saunders 2008; 84- 94.

7. Maureen S, Mark R, Suzanne A, and Ronald JE. Positive interference in lithium determinations from clot activator in collection container. Clin Chem 1997; 43(4): 675-679.

8. Raffick AR, Bowen ATR. Interferences from blood collection tube components on clinical chemistry assays. Biochem Medica 2014; 24(1): 31-44 